\title{
¿A DÓNDE VAN LAS \\ UNIVERSIDADES? PERSPECTIVAS \\ HISTÓRICA Y COMPARATIVA
}

Stefan Collini*

T os lectores habrán advertido que en las últimas dos o tres décadas

las empresas de todo el mundo se han visto presionadas para que se parezcan cada vez más a las universidades. Se las ha exhortado a que abandonen la competencia comercial y modelen su comportamiento siguiendo pautas de colaboración académica. Las empresas que cotizan en bolsa deben obtener rendimientos que detallen el valor intelectual y académico de sus productos y servicios. Las metas y parámetros de referencia son sustituidos por juicios informados, los departamentos de recursos humanos se reducen, las empresas hacen menos auto publicidad y producen menos folletos elegantes. También han adoptado esquemas de dirección más colegiados y de abajo hacia arriba; los directores ejecutivos son sustituidos por comités escogidos entre el profesorado, y los cargos en las juntas directivas de las principales empresas se reservan a experimentados profesores titulares de historia medieval.

A primera vista puede parecer obvio por qué los cambios que hoy ocurren en realidad son exactamente opuestos a los que acabo de esbozar en términos imaginaros. Es casi un lugar común observar que las universidades están ahora sometidas a una "intimidación incesante" por su fracaso para asemejarse a una empresa de negocios. Pero cabe

\footnotetext{
* Profesor de Historia Intelectual y Literatura Inglesa, Universidad de Cambridge, uk, [sc107@cam.ac.uk]. Este ensayo es el capítulo primero de su libro Speaking of universities, Londres y Nueva York, Verso, 2017. La traducción, de Alberto Supelano, se publica con las autorizaciones correspondientes. Fecha de recepción: 06-03-2017, fecha de aceptación: 04-09-2017. Sugerencia de citación: Collini, S. (2017). ¿Qué les ocurre a las universidades? Perspectivas histórica y comparativa, Revista de Economía Institucional 19(37), 13-29. Dor: https://doi.org/10.18601/01245996.v19n37.02
} 
recordar que hace ya mucho tiempo el capitalismo padeció, de algún modo, la reciente epidemia de la envidia comercial. No debemos caer en una esencialización ahistórica del capitalismo ni de las universidades -y hay mucho que decir de sus cambios a través del tiempo-, pero de algún modo coexistieron durante algo más de un siglo sin exigir que las universidades adoptaran las metas, estructuras y procedimientos de las empresas o, al menos, de algún modelo de escuela de negocios sobre cómo deben funcionar las empresas. De hecho, casi 150 años después de que las universidades empezaron a asumir su forma moderna a comienzos del siglo XIX, una de las justificaciones de su existencia era que constituían un antídoto o reflejaban una ética alternativa a la del mundo comercial. Esta opinión era compartida incluso por quienes en retrospectiva son citados como paladines de la ciencia aplicada, como T. H. Huxley, quien en 1894 declaró: “E1 negocio primordial de las universidades solo tiene que ver con el conocimiento puro y el arte puro, independientes de toda aplicación práctica; con el avance de la cultura y no con el aumento de la riqueza o de las mercancías". Esta concepción fue respaldada por uno de los líderes emblemáticos de ese mundo comercial, Joseph Chamberlain, alcalde de Birmingham, y después ministro del gabinete, quien saludó la creación, en su feudo, de lo que se convertiría en la Universidad de Birmingham diciendo: "Fundar una universidad en medio de una gran población industrial y manufacturera es hacer algo para infundir en las masas objetivos más altos y mayores ambiciones intelectuales que los que serían posibles para personas dedicadas enteramente al comercio y las actividades mercantiles". Algo similar afirmó, en forma más categórica, Ernest Rutherford, el "padre de la física nuclear" que ganó el Nobel, cuando advirtió a la Universidad de Bristol en 1927 que "consideraría un desastre el uso de laboratorios universitarios para investigaciones relacionadas con la industria".

Cito esas opiniones porque son muy distantes de los supuestos sobre la relación entre universidades y economía que damos cada vez más por sentados, aunque fuesen parte de una corriente de pensamiento sobre las universidades arraigada, y quizá la dominante, hasta bien entrada la segunda mitad del siglo xx, especialmente en Gran Bretaña y en las partes del mundo con influencia británica. Aunque nunca fue, por supuesto, la única corriente, porque las variantes del conflicto entre quienes afirman la prioridad de las preocupaciones prácticas y quienes pretenden representar valores no instrumentales tienen una larga historia. El hecho es que lo que las sociedades han deseado de sus universidades ha variado históricamente y ha sido 
internamente contradictorio, y solo alcanzable en parte. Nosotros deberíamos empezar reconociendo que las universidades siempre han servido a fines prácticos y ayudado a preparar a sus graduados para un empleo. En una época su papel principal era enseñar la religión verdadera y proporcionar hombres educados a la Iglesia; en otra época era inculcar virtud o buen juicio o buenos modales o cualquiera de los supuestos atributos de un caballero; y en otra, seleccionar, equipar y moldear a quienes ocuparían posiciones de liderazgo en el Estado, el imperio o la sociedad; y, a menudo, alejar a los jóvenes de las malas acciones y mantener viva la llama del conocimiento. ¿Cuál es, entonces, la peculiaridad de los cambios de las dos o tres últimas décadas? ¿Los críticos exageran y los cambios son tan solo una mutación más en la historia de la adaptación necesaria de las universidades para servir a las necesidades cambiantes de sociedad?, o ¿hay algo característico que puede ser perjudicial en un plazo más largo del que hoy percibimos? Quizá sea aquí donde pueden ayudar las perspectivas histórica y comparativa. Pero primero debo advertir a los lectores que este escrito contiene material de carácter ético explícito. Porque si nos limitamos al lenguaje de los informes empresariales, con su incesante optimismo acerca de la productividad, el flujo de ingresos, las asociaciones comerciales y los emprendimientos internacionales, no tendremos manera de distinguir entre las actividades de las universidades y las de las empresas de negocios a cuya imagen se están remodelando.

\section{II}

Desde comienzos del siglo xix, el ideal de Humboldt fue el que más contribuyó a moldear las universidades en los 150 años siguientes. Este destacaba la búsqueda y transmisión de conocimiento y su conversión en Wissenschaft (ciencia). En este modelo era esencial la autonomía profesional del académico, y la enseñanza se concebía como una forma de aprendizaje. Pero junto a las diversas formas de preparación para el empleo, otros dos ideales complicaron esta concepción de la universidad como hogar protegido de libre investigación. E1 ideal colegiado se centró en relaciones estrechas estudiante-profesor en un ambiente residencial cuyo objetivo era formar el carácter, bien fuese mediante la enseñanza inspiradora, el esfuerzo atlético o el contagio de los pares. Y el ideal cívico dio prioridad a formar ciudadanos e inculcar una ética compartida, bien fuese de élite o republicana o democrática, lo que implicaba desarrollar talentos y formas de experiencia que ayudaran a definir y fortalecer la identidad del Estado. La mayoría de las universidades de Europa continental incorporaron una mezcla de ideales 
humboldtianos y cívicos; la tradición inglesa, derivada de Oxbridge, pero no la tradición escocesa, tendió a poner en primer plano el ideal colegiado, mientras que diferentes tipos de instituciones en Estados Unidos combinaron los tres ideales en diversas proporciones.

Pero en todos estos lugares el contrato implícito entre universidad y sociedad aceptaba que el valor distintivo de la educación superior consistía en cultivar aquellas formas de erudición, ciencia y cultura cuya relación con las preocupaciones instrumentales y mundanas de la vida práctica era indirecta y de largo plazo, y a veces antagónica. También implicaba dar cierto grado de autonomía profesional a quienes realizaban tales investigaciones, una convención que parece natural tanto por el carácter elitista de la educación superior hasta las últimas décadas del siglo xx como por la persistencia de las formas de deferencia cultural y social asociadas.

Las décadas posteriores a 1945 vieron una expansión de los sistemas de educación superior, encabezada por Estados Unidos, aunque el crecimiento numérico no produjo cambios sustanciales en la concepción ni en la estructura de las universidades. Más bien sucedió lo contrario, pues las universidades fundadas para liderar un nuevo modelo -bien fuese de relación estrecha con la industria local o de formas interdisciplinarias no departamentales- se asemejaban cada vez más a los modelos dominantes. En Gran Bretaña y otras partes del mundo de habla inglesa eran en gran medida autónomas. Los consejos de facultad no eran meros cuerpos decorativos, las humanidades y las ciencias puras preponderaban y fijaban el tono intelectual, y el pregrado (había pocos estudiantes de posgrado), para estudiantes internos cuyo ingreso era muy selectivo, solía tener buenas instalaciones deportivas. Las nuevas universidades de los años sesenta, en Gran Bretaña y en otras partes, podían haber aspirado a trazar "un nuevo mapa de enseñanza", pero en la práctica hicieron posible que una porción mayor de hijos de la clase media, en especial de hijas, asistiera a lo que en esencia eran instituciones muy tradicionales. Sería una simplificación excesiva, aunque quizá útil, decir que, en su forma de gobierno, en su carácter intelectual y en sus relaciones con la sociedad anfitriona, las universidades de los años setenta estaban quizá más cerca de las de cincuenta o setenta años atrás que de las de treinta o cuarenta años después.

Los drásticos cambios que han ocurrido en las últimas décadas, sobre todo en Gran Bretaña, ponen en tela de juicio muchos de los supuestos que sostuvieron a las universidades durante el siglo anterior o algo más. Una de las cosas que más me ha impresionado en las 
discusiones recientes con personas que participan en debates sobre educación superior en otros países es que muchas de ellas observan la evolución de Gran Bretaña con una mezcla de tristeza y temor. Tristeza porque era un sistema universitario que admiraban, y temor porque sienten que muchos de los cambios que se impusieron en las universidades de Gran Bretaña pronto se extenderán a otros sistemas europeos centralizados y a sistemas más plurales y diversos de otras partes del mundo.

Esto se debe, en parte, a que hay un elemento de calco cuando algunos gobiernos o administraciones universitarias adoptan medidas de otros países que juzgan ventajosas ante sus propias circunstancias. Pero, cuando miramos más de cerca, vemos que los patrones son tan marcados y sincronizados con cambios similares en otras esferas de la sociedad que sugieren que lo que presenciamos no es solo cuestión de políticas, o de la política de un grupo actualmente en el poder en cualquiera de esos países, sino el resultado de ciertos cambios sociales y económicos de más largo plazo. Así, dejando a un lado las especificidades culturales, permítanme resumir una historia que hoy se cuenta, casi con las mismas palabras, en muchas de las sociedades desarrolladas. Como se verá, esta historia se aplica del modo más obvio a la experiencia de universidades de Estados Unidos y Gran Bretaña, pero como durante gran parte del periodo relevante han sido los modelos dominantes, o los principales, cabe esperar que así suceda en otras partes.

He aquí la mejor versión de esa historia sobre la historia reciente de las universidades.

El periodo de 1945 a mediados de los setenta fue de expansión en todas las sociedades desarrolladas, lo que los franceses llaman les trente glorieuses, tres décadas de recuperación y prosperidad. Como parte del crecimiento general, la educación superior y la investigación aumentaron a una tasa sin precedentes. Las cifras crecieron en todas partes, pero en ninguna parte más que en Estados Unidos, inducidas por la G. I. Bill [Ley de Reajuste del Personal de Servicio de 1944] pero alimentadas por la promesa de movilidad social a millones de personas que eran las primeras de su familia en acceder a educación superior. Además, los gobiernos de todas partes, de nuevo encabezados por Estados Unidos, dedicaron dinero a investigación científica de un modo que aumentó el tamaño y amplió el papel de las universidades en general. En esos años, las universidades mantuvieron gran parte del estatus y la autonomía que habían conseguido durante el siglo, o más, en que eran mucho más pequeñas y estaban íntimamente ligadas a las élites dominantes. Desde finales del siglo xix hasta mediados del siglo xx, sus funciones más limitadas fueron respetadas por un amplio consenso, aunque en su mayoría solo desempeñaron un pequeño papel en sus sociedades y sus economías, usualmente lejos de la atención pública. Pero desde los años cuarenta fueron objeto de políticas del gobierno y de la atención pública. Aunque su escala y su visibilidad cambiaran, su carácter fundamental poco se modificó. En general, el claustro académico 
aún establecía el tono de sus instituciones, las humanidades y las ciencias puras seguían siendo las disciplinas más prestigiosas e institucionalmente dominantes, y la sociedad seguía respetando a las universidades como uno de los principales hogares de la "cultura" de tipo tradicional, la cual aspiraban adquirir las clases menos privilegiadas. La expansión empezó a someter a presión todas estas características de las universidades, pero la prosperidad económica y el enorme crecimiento de la financiación pública en Europa, o una mezcla de financiación federal y de fundaciones en Estados Unidos, llevó a que, en ese entonces, se pudiera pasar por alto la difícil elección entre las diversas funciones de las universidades.

Sin embargo -continúa la historia-, este solo era un equilibrio temporal e inestable. Las universidades vivían de capital cultural prestado y de un flujo de capital real que pronto se reduciría. A medida que las sociedades desarrolladas, encabezadas por Estados Unidos, pasaban de una educación superior de élite a una educación masiva, a medida que decaía la deferencia tradicional o el respeto a la cultura de élite, a medida que aumentaba la demanda de formación profesional en ciencias vocacionales y aplicadas, y a medida que estas sociedades sustituían el ideal de autonomía profesional por el de responsabilidad pública, se sostenía cada vez más que las universidades debían cambiar. Y cambiaron desde los años ochenta, a pesar de las protestas de académicos que confundían la buena fortuna contingente de las décadas posteriores a 1945 con la esencia eterna de la universidad. En los últimos treinta años -que los críticos consideran les trente glorieuses- las universidades empezaron a modernizarse. Hoy se reconoce su papel esencial como motor del crecimiento económico, y sus actividades se ajustan cada vez más a las necesidades de la industria, las finanzas y el comercio. Su financiación se adapta a los principios de la economía de mercado, sus estudiantes, conscientes de la deuda, buscan la mejor relación calidad precio y los usuarios de la investigación contratan y pagan los proyectos de investigación. La satisfacción del cliente es la prueba verdadera de su éxito en un mercado competitivo. La gerencia sustituye a la administración. Un equipo de alta gerencia se sitúa en la cúspide de la estructura ejecutiva y todas las instituciones tienen un plan de negocios adecuado. Internamente, las escuelas profesionales y las disciplinas vocacionales y biomédicas tienen un peso preponderante debido a que son los programas que más ingresos generan.

Estas - cuenta la historia- son adaptaciones buenas y necesarias al cambiante mundo de las sociedades modernas que compiten en una economía global. Pero los cambios aún son insuficientes. Como hacen las demás empresas minoristas, las universidades deben fijar precios diferenciales a sus bienes, según la demanda; es necesario entonces que haya más variación de precios entre universidades y entre cursos. En toda la organización se deben usar sistemáticamente los indicadores clave de desempeño para medir logros y eliminar fallas. Las empresas comerciales deben tener más voz en qué se enseña, qué se investiga y cómo se prestan estos servicios. La titularidad es un obstáculo para la gestión racional de la movilidad laboral, y se debe eliminar. Y es necesario adoptar nuevas tecnologías y usar de manera más intensiva el tiempo y la planta para acelerar la producción y reducir los costos. En comparación con las universidades de treinta años atrás, muchas instituciones actuales han cambiado hasta casi no reconocerse; pero conforme al esquema de McKinsey para una evaluación organizativa rigurosa, tienen mal desempeño, costos fijos excesivos y una planta de personal inflexible, junto a un anticuado ethos colectivo, una deficiente comercialización de sus servicios y una lenta adaptación al cambio tecnológico. Y, en particular, en las universidades aún hay personas, en especial profesores titulares (sobre todo en humanidades), que se resisten a estos cambios y se aferran a un ideal nostálgico de universidad que solo se 
adaptó en parte a las condiciones sociales de ayer. Su crítica a cualquiera de estos cambios en nombre de una "idea de universidad" se debe denunciar y rechazar, como el quejido egoísta de una élite plumífera que no entiende, o quiere negar, el carácter y el ritmo del cambio social y económico. En suma, lo que se necesita es más dinamismo estratégico (para usar el degradante lenguaje gerencial que barre todo lo que le precede).

Esa es la historia, o al menos una de ellas. Es un relato influyente y, lo que, es más, una historia que tan solo presenta la evidencia suficiente para que parezca verosímil. Después de todo, parte de lo que dice de la historia de las universidades en sus relaciones con las sociedades que las acogen desde 1945 es cierta. Pero cabe hacer tres observaciones. La primera es que, igual que todas las teorías deterministas de la historia, este relato tiene confusiones con respecto a la agencia. Considera que reconocer y adaptarse a los cambios sociales mencionados es una acción racional libremente elegida, pero "oponerse" a ellos es autodestructivo y al final imposible. Segunda, supone que los cambios en la sociedad se reproducen de la misma forma en las universidades, sin reconocer que la relación es más dialéctica. Y tercera, no explica qué es lo característico de las universidades y de lo que hacen. La universidad se considera un negocio como cualquier otro y, por tanto, sujeta a las mismas leyes que rigen el cambio en los negocios.

Así, ¿cómo podemos cuestionarla quienes no la encontramos totalmente convincente? Los lectores habrán advertido que cuando narré esta breve versión utilicé progresivamente el vocabulario de la consultoría empresarial, que impregna cada vez más la discusión de este y otros temas en la política y los medios de comunicación. Un gran paso que podríamos dar para contar una historia más adecuada es utilizar un vocabulario apropiado para las actividades que se están discutiendo. Esto, a su vez, implica reflexionar sobre qué distingue a la universidad de otras instituciones sociales. Y, como siempre, una manera de contrarrestar una historia mala, selectiva y tendenciosa es escribir una mejor, más extensa y más analítica. Este escrito intenta ilustrar brevemente algunos de los beneficios de seguir estas tres estrategias, y algo que quizá pueda hacer aquí sea dar una idea de cómo se han interpretado recientemente estos asuntos generales en el debate público y la política en Gran Bretaña. Para personas de otros países, esto cumplirá al menos la misma función de los cortos de las "próximas películas" en el cine, porque estos asuntos pronto llegarán a una universidad cercana, aunque con subtítulos.

Antes de proseguir, quisiera evitar tres posibles malentendidos. Primero, ni aquí ni en mi libro anterior ${ }^{1}$ propongo un ideal o una

1 What are universities for?, Londres, Penguin Books, 2012 [N. del T.]. 
esencia, una manera de distinguir entre universidades supuestamente "reales" e instituciones que no merecen ese nombre. Reflexiono, en cambio, sobre diversos tipos que han surgido en todo el mundo, en particular, en los dos últimos siglos, y sobre sus relaciones con las sociedades anfitrionas. Segundo, no propongo entonces una historia de decadencia; hay quienes afirman que solía haber lo que llaman universidades "reales" pero que hoy se han degradado o destruido. De ningún modo. Creo, como he intentado aclarar en muchas ocasiones, que la expansión de la educación superior ha sido un gran logro democrático que debemos seguir apoyando. Y tercero - y querría ser muy enfático a este respecto-, no digo que las universidades no sirvan o deban servir a varios fines prácticos. Siempre lo han hecho y supongo que siempre lo harán. Hace tiempo eso significaba preparar principalmente un pequeño número de hombres al servicio de la Iglesia, y más tarde al servicio del Estado. En una época posterior ayudaban a dar algún brillo y un sello social legible a un caballero, y después ayudaron a inculcar la moral cristiana y a formar el carácter. Llegaron a constituir un hogar para la "educación superior", entendida como una forma principalmente curatorial de erudición, y cada vez más como trabajo original en ciencias naturales. En la primera mitad del siglo $\mathrm{xx}$, su papel principal era formar una élite que ocupara cargos de liderazgo en la sociedad, cultivar la erudición original y la investigación científica y proporcionar luces culturales a sus comunidades locales. Pero los líderes políticos nacionales y locales, los capitanes de industria, las iglesias, el ejército y cualquier grupo de la sociedad bien financiado o bien intencionado $-\mathrm{O}$, a veces, bien financiado $\mathrm{y}$ bien intencionado- también les encargaban diversas tareas prácticas.

No obstante, por importantes o valiosas que fueran esas sucesivas tareas externas, no son toda la historia, y una manera de pensar en lo que distingue a las universidades es decir que proporcionan un espacio parcialmente protegido dentro del cual el intento de ampliar y profundizar la comprensión humana tiene prioridad sobre otros propósitos de un modo que sería disparatado -o al menos perjudicialpara otras instituciones. No sugiero (sobraría decirlo) que la buena reflexión solo provenga, o pueda provenir, de las universidades. Pero pienso que estas son las únicas instituciones donde esa reflexión no se subordina, en principio, a otro propósito. En consecuencia, durante su larga historia ha habido una continua tensión entre los fines prácticos que la sociedad cree promover al fundar o apoyar universidades, y el ineludible impulso hacia la investigación abierta que ha moldeado a estas instituciones a través del tiempo. La apertura de sus principales 
actividades amenaza con legitimar formas de investigación contrarias a los objetivos de quienes las fundaron o apoyaron. De hecho, cabe preguntar si las sociedades no hacen una especie de pacto faustiano cuando fundan universidades: les piden que sirvan a diversos propósitos prácticos, pero si se les da la libertad intelectual necesaria para servir apropiadamente a esos propósitos, siempre tenderán a exceder o a menoscabar esos propósitos.

Al mismo tiempo, hay una profunda tensión en la relación entre las universidades y sus sociedades matrices. Un conjunto de actividades cuya lógica informativa requiere la investigación abierta y el ejercicio del juicio cualitativo está siempre en una especie de colisión con la tendencia de las sociedades modernas a exigir formas cuantitativamente medibles de responsabilidad y de resultados utilitarios. Para expresarlo en términos deliberadamente provocativos, lo más distintivo, y quizá característicamente valioso, de lo que hacen las universidades es aquello que no pueden captar las métricas que las sociedades usan cada vez más para medir el valor.

\section{III}

Un elemento común a muchas de las variantes de la actual moda política de hacer "responsables" a las universidades es que los intentos bienintencionados de demostrar su "relevancia" para las necesidades de la sociedad pueden terminar siendo contraproducentes. E1 núcleo del problema consiste en que se intenta pasar muy rápidamente de las actividades que se realizan en las universidades a los beneficios que la sociedad puede obtener de ellas. Las versiones de este error son evidentes, por ejemplo, en la discusión sobre los vínculos entre universidades y empresas locales, donde se ha de reconocer que las relaciones más provechosas suelen surgir cuando los departamentos universitarios se concentran en hacer el tipo de investigación en que son diestros, en vez de intentar adivinar las necesidades actuales (y quizá temporales) de ciertas empresas, y luego adaptar su investigación para satisfacerlas. Y, de nuevo, con frecuencia se ha señalado que los empleadores no necesariamente quieren graduados a los que se ha impartido una formación estrecha que los capacita para un tipo particular de empleo. Tales empleos y su demanda cambian con rapidez y el enfoque de dichos graduados tiende a ser muy estrecho y su manera de pensar demasiado rígida. Un graduado que se ha beneficiado de una educación intelectualmente rigurosa y culturalmente amplia servirá mucho mejor a las necesidades de muchos empleadores en el largo plazo. Y, como argumenté en otro lugar, algo similar se aplica 
al mal concebido criterio de "impacto" del Marco de Investigación de Excelencia de Gran Bretaña: aunque es esencial que se expongan argumentos convincentes de los beneficios que la sociedad recibe de la investigación científica y académica, se ha de reconocer que son indirectos y de largo plazo. Volver obligatoria la búsqueda de ciertas formas estrechas de impacto económico y social en el corto plazo termina perjudicando la calidad de la investigación y reduciendo sus beneficios para la sociedad. En otras palabras, en todos estos casos la sociedad obtiene los mayores beneficios de las universidades animándolas a concentrarse en las cosas en que son diestras, y no tratando de convertirlas en una especie de laboratorio o centro de capacitación empresarial.

Pero, por la misma razón, quienes participan en la vida académica deben ser cuidadosos antes de reclamar todo tipo de beneficios sociales para las universidades. Entre los defensores de las universidades se tiende a mostrar que contribuyen a todo bien moral o social aceptado, incluidos la promoción de la igualdad de respeto, la movilidad social y la gentileza. Y, además, a mostrar que las universidades son por naturaleza congruentes con todos los valores liberales aceptados. Me parece que este es un error así como una cuestión de hecho y de táctica. En estos días el término "elitista" se usa para condenar cualquier argumento o posición, pero creo que debemos reconocer que las universidades son en varios sentidos intrínsecamente elitistas en un significado restringido de ese término. Es cierto que la investigación intelectual es democrática en un sentido irreductible: los mejores argumentos y la mejor evidencia son decisivos, sin importar quien los exponga. Pero en otro sentido es selectiva: no todo el mundo es igualmente hábil para realizar la investigación en el nivel apropiado. Y donde estos valores chocan, la prioridad de las universidades debe ser ampliar la comprensión, no fomentar valores secundarios deseables, por incómoda que pueda ser esta posición. No creo que debamos poner todos los huevos en el canasto de fomentar la movilidad social, en parte porque es en sí misma una noción confusa, que a menudo se reduce a los efectos de la prosperidad a largo plazo y a sustituir el trabajo manual por el de cuello blanco, pero también porque justificaría las actividades universitarias solo en términos de los patrones de empleo de los graduados, justamente el tipo de valoración reduccionista e instrumental que debemos combatir de modo más general. Además, debemos considerar con mucho escepticismo el supuesto de que tres años de residencia entre un grupo seleccionado de pares llevan por sí mismos a hacernos a todos mejores personas. A algunas personas las 
puede entristecer que las universidades no sean formas colectivas de asesoramiento en relaciones o versiones extendidas del tipo de fin de semana en el que el lanzamiento de bolas de pintura o el rafting libera al amigo interno en todos nosotros. Y, por último, también debemos reconocer que, en la práctica, las universidades actuales no hacen muy bien algunas de sus tareas distintivas. No reconocerlo sería, de nuevo, subestimar la inteligencia del público, que es consciente de que no todo está bien en muchas de nuestras superpobladas y excesivamente reguladas instituciones de educación superior.

Tampoco debemos permitir que la actual retórica fundamentalista de mercado nos induzca a idealizar una versión imaginaria de la educación superior en Estados Unidos. Todas las comparaciones internacionales están dominadas por las principales universidades de investigación estadounidenses cuyo supuesto éxito ha adquirido un estatus casi mítico en las fantasías y aspiraciones de los responsables de las universidades de otros países. También se supone que su ejemplo es un poderoso argumento en favor de las universidades privadas y de un mercado libre para todo. Hay mucho que decir aquí, incluyendo, como Howard Hotson demostró de manera concluyente hace poco, que la educación superior estadounidense es más derrochadora y costosa que la de muchos otros sistemas nacionales. Pero permítanme hacer otras tres breves observaciones.

Primera, no hay un "sistema de educación superior" en Estados Unidos: la ecología es diversa y compleja, y hoy abarca casi 4 mil instituciones de diverso tipo. El hecho de que la mayoría de sus universidades más prestigiosas sean privadas significa que corremos el riesgo de percibir erróneamente la realidad de la educación superior en ese país. Es instructivo recordar que el $70 \%$ de los estudiantes estadounidenses asisten a instituciones públicas, y que esta es una proporción mayor que la de algunos países europeos. Los estereotipos son aquí engañosos. En Escandinavia esa cifra llega al 100\%. De manera confusa, la ocDE clasifica las universidades británicas como privadas - usando un término extraño, "universidades privadas dependientes del gobierno"- y esto suscita conclusiones muy curiosas. Por ejemplo, sus cifras muestran que la proporción del gasto en educación superior proveniente de fuentes privadas es mayor en el Reino Unido que en casi todos los demás países, y mucho mayor que en Estados Unidos, una conclusión inverosímil. Este es un ejemplo clásico de que las estadísticas son tan útiles y confiables como las definiciones en las que se basan. 
Segunda, a menudo nos dicen que los procedimientos de admisión “ciegos a las necesidades" combinados con becas generosas a los solicitantes de estratos menos privilegiados demuestran que el sistema de altas matrículas es compatible con la exigencia de justicia social y el deseo de movilidad social. Pero la realidad es que la educación superior estadounidense es al menos tan estratificada por clase social como en otros países, y que las grandes ventajas de los hijos de familias acomodadas incluyen la mayor posibilidad de ser admitidos en las universidades más selectivas. Quienes tengan dudas podrían considerar solo una cifra: el ingreso promedio de los padres de estudiantes de pregrado en Harvard es de 450.000 dólares al año.

Tercera, muchos de los cambios hoy en curso en los sistemas de educación superior de Gran Bretaña y otros países pretenden asemejarlos a lo que se supone son las características de las instituciones estadounidenses más exitosas. Pero una característica notable de esas instituciones es que el profesorado titular mantiene, colectivamente, un estatus y un poder que hoy no se otorga a sus pares de cualquier universidad británica fuera de Oxbridge, y que, cuando actúa unido, el profesorado de las principales universidades estadounidenses constituye una fuerza que los presidentes y los fideicomisarios deben tener en cuenta, como ilustran los casos de Larry Summers en Harvard y de Teresa Sullivan en Virginia (el profesorado desempeñó un papel importante en el retiro de Summers como presidente y en la reincorporación de Sullivan después de ser despedida). Además, la base institucional del profesorado sigue siendo el departamento, el cual es una sorprendente y duradera característica de las universidades de investigación estadounidenses y el hogar natural de aquellos estándares y protocolos cuya transmisión de generación en generación es el aspecto central de la calidad académica. La abolición de los departamentos, o su sustitución por unidades más grandes o por centros y programas interdisciplinarios, hoy tan de moda en Gran Bretaña y Australasia, debilita la autonomía académica y da poder a los gerentes. Si se considera que el historial de las universidades estadounidenses más prestigiosas es una guía en estos asuntos, se debería reconocer que la clave para conservar la reputación académica es mantener departamentos sólidos.

\section{IV}

Hasta ahora solo he sugerido algunas maneras de aprovechar las perspectivas histórica y comparativa para cuestionar la ortodoxia fundamentalista de mercado reinante con respecto a la educación su- 
perior. Pero como insto indirectamente a algunos colegas académicos a salir a la palestra, puede ser apropiado exponer una o dos reflexiones sobre el tipo de misiles que pueden lanzarnos. Con base en mi experiencia diría que parte de lo que provoca hostilidad es que, para un académico establecido en una universidad prestigiosa, sugerir que algunas medidas políticas o administrativas actuales frustran en vez de promover los propósitos verdaderos de la universidad es acusarla de ser "superior", o de despreciar las preocupaciones de la gente común, o de creer que tiene un derecho inmerecido. En algunos círculos se opina que sería mejor que los académicos guarden silencio sobre estos asuntos, o si alzan la voz en forma imprudente, que reconozcan su buena fortuna, disculpen las fallas de las universidades en el pasado y se comprometan a trabajar hombro a hombro en el futuro para ir más allá de la excelencia, y versiones corporativas similares de la noción maoísta de autocorrección.

A este respecto, deseo indicar que he oído replicar que se es incomprendido o se está mal informado, pero sean cuales sean los riesgos, creo que es algo que se debe explorar. Por desgracia, he tenido la oportunidad de meditar sobre la hostilidad que encuentran, en algunos círculos, quienes intentan defender las universidades en términos apropiados. Como ya dije, creo que entre el público en general existe bastante interés y buena voluntad hacia las universidades, y que al dirigirse a ese público no es necesario ser apologético ni defensivo. Pero en ciertos círculos, en particular entre los que comentan estos asuntos en la arena política, en los medios de comunicación, en la blogosfera u otros espacios de discusión pública, hay, sin duda, una carga de hostilidad y resentimiento que puede encontrar quien intente caracterizar y destacar el valor de la vida intelectual propia de las universidades. Es claro que un antiintelectualismo más amplio se alimenta de ella, el cual fue bien descrito en Estados Unidos al menos desde Richard Hofstadter y diagnosticado brillantemente por Thorstein Veblen y otros, años antes ${ }^{2}$.

La versión más estrecha de esta respuesta considera escandaloso que los académicos critiquen o se quejen de cualquier cosa relacionada con la universidades y el apoyo y la regulación de la sociedad que las acoge. Junto a razones más comprensibles y quizá más justificables de esta reacción, debemos reconocer -y es aquí donde sé que estoy más expuesto a malentendidos- la fuerza de lo que Nietzsche llamó

${ }^{2} \mathrm{E} 1$ autor alude a Hofstadter, R, Anti-intelectualismo en la vida nortemericana [1963], Madrid, Tecnos, 1969, y Veblen, T. The higher learning in America: A memorandum on the conduct of universities by businessmen, Nueva York, Huebsch, 1918 [N. del T.]. 
resentimiento. En esa reacción hay una amargura, una combinación de ira y de burla, junto a una intención niveladora, que va más allá de lo que requeriría cualquier desacuerdo real sobre el tema. Y si se me permite una rápida incursión en la fenomenología especulativa, creo que esta reacción, por su hostilidad y desprecio, refleja el sinuoso reconocimiento de que hay algo deseable e incluso envidiable en el papel del académico o del científico. Parte de la reacción obedece, por supuesto, al resentimiento hacia la supuesta seguridad de la titularidad en un mundo con empleos muy poco seguros; otra parte, a la sensación de cuánta autonomía, comparativamente hablando, tienen los académicos en su vida laboral, cuánta flexibilidad en la elección de su horario de trabajo, etc., en un mundo donde la mayoría de la gente tiene poca autonomía. Y, en parte, también al reconocimiento, de mala gana, de que los asuntos en que trabajan los académicos y los científicos son en sí mismos más interesantes, gratificantes y quizá humanamente valiosos que los asuntos a los que la mayoría de las personas deben dedicar sus energías en su vida laboral.

Es preciso añadir que esto coexiste con la convicción paralela de que los académicos son inconscientes o están protegidos de las grandes necesidades económicas de la vida, y siempre necesitan un fuerte recordatorio de la fuente de sus salarios en ese duro mundo de pérdidas y ganancias que hace posible todo lo demás. Por tanto, aquí hay una compleja etiología emocional. Los académicos son a la vez objetos de envidia y resentimiento porque su papel parece permitirles tratar asuntos intrínsecamente gratificantes mientras que son financiados por el trabajo de otros que no tienen el privilegio de dedicarse a esos asuntos. A esta reacción le agradaría que el viento gélido de la necesidad económica - el clima en que transcurre la vida de la mayoría de las personas- soplara con más fuerza en las protegidas arboledas del mundo académico. Y se considera simplemente insoportable la idea de que, desde esta posición privilegiada y protegida, los académicos osen quejarse de los intentos de hacer que sus actividades sean democráticamente responsables de la única manera en que la democracia hoy entiende esa operación. No dudo que estas reacciones, en términos más o menos semejantes, son reconocibles para cualquier lector, pero sugiero que también debemos ver que, al mismo tiempo, implican un reconocimiento encubierto del valor y la deseabilidad humana de lo que hacen los académicos y los científicos. Parte de la ira reprimida que es uno de los ingredientes de este resentimiento proviene de la lucha contra una ambivalencia inconfesable. Si los académicos mantuvieran parte de sus condiciones de empleo relativamente favorables 
pero dedicaran su jornada diaria al trabajo, equivalente al de romper piedras, de un empleado de oficina, en otros grupos de la sociedad aún podría haber la sensación de que estos académicos no lo hacen muy mal, pero quizá habría menos ira alimentada por el resentimiento.

Por supuesto, una característica de todos los análisis fenomenológicos es que, ante una duda escéptica, no pueden establecer su verdad apelando a evidencias externas incontrovertibles. Dichos análisis piden el reconocimiento de una redescripción de un aspecto particular de la experiencia humana, y si no hay reconocimiento compartido en el cual basarse, su poder de persuasión es limitado. Pero quizá en otros campos de experiencia no haya nada sorprendente en la idea de que la vehemencia de una reacción negativa ante una actividad es directamente proporcional al sordo reconocimiento de que allí hay algo complejo que, de una u otra forma, sería deseable o valedero.

A pesar de estos y otros riesgos, insto a mis colegas académicos a que ayuden a exponer los diversos argumentos a los públicos relevantes en la variedad de estilos que sean necesarios. Por mi parte, primero he intentado cuestionar la concepción estrecha de las universidades como meros institutos para capacitar fuerza de trabajo y aplicar descubrimientos que generen crecimiento económico. Pero no sería difícil pintar una imagen distópica del lugar al que se dirigen las universidades si los desarrollos actuales siguen sin control, aunque debo aclarar que no comparto las formas más extremas de pesimismo. Una ventaja de tener cierta familiaridad con la historia de los debates sobre las universidades durante el siglo anterior o algo más es que sirve de antídoto contra el alarmismo ahistórico y el casandrismo rampante. Los comentaristas de cada generación han pensado que todo iba al garete, pero en ese caso la zozobra puede durar más de lo esperado. Así como la teología nunca volverá a ser la reina de las ciencias ni el latín el sello distintivo de una persona culta, otras verdades que una vez se dieron por sentadas en las universidades desaparecerán sin que llegue el Armagedón. Aun así, ¿cuál sería la predicción más sombría si las tendencias que he mencionado continuasen sin obstáculos? Esa oscura imagen podría incluir lo siguiente.

E1 carácter dominante de las instituciones de educación superior en todo el mundo sería el de empresas especializadas en capacitar personas para trabajar en los negocios. Más allá de eso, un buen número de instituciones de alta matrícula combinarán la docencia de una escuela secundaria avanzada con elementos de investigación por contrato para organizaciones externas. Un número selecto de otras instituciones más pequeñas, en su mayoría privadas, impartirá una educación cultural amplia ante todo a hijos de familias relativamente ricas. $\mathrm{Y}$ un número mucho menor de instituciones históricamente prestigiosas, con buen apoyo financiero, combinará la enseñanza a una capa 
muy selecta de estudiantes con formas diversas de erudición e investigación en algunos campos tradicionales de investigación, aunque con gran preponderancia numérica y financiera de las ciencias biomédicas y aplicadas y de la formación profesional, especialmente en los negocios y el derecho. En todos esos tipos de instituciones habrá una reducida proporción o la eliminación total de los académicos titulares y un enorme aumento de los profesores ocasionales, mientras que los vestigios de autonomía académica desaparecerán por completo. Habrá mucha menos enseñanza cara a cara o en grupos pequeños, y mucha mayor dependencia de la tecnología. Los estudiantes se sentirán cada vez más con el derecho a los buenos resultados por los que han pagado. Las humanidades serán marginadas aún más y serán estudiadas en su mayor parte por los hijos de familias ricas.

Las universidades más selectivas se verán cada vez más presionadas para ofrecer mejores instalaciones: se acelerará la "carrera armamentista de comodidades”, y será más difícil distinguir entre universidades y diversos tipos de hoteles de lujo o centros de spa. Las universidades dependerán cada vez más de la matrícula de estudiantes extranjeros, y la venta de sí mismas en estos mercados moldeará cada vez más sus políticas internas. La deuda estudiantil se disparará y será una causa cada vez mayor de división social. Hacer responsable a cada universidad de los préstamos de sus estudiantes incentivará la producción de graduados de altos ingresos, que son el mejor riesgo financiero. El crecimiento de las universidades privadas, y en especial con ánimo de lucro, seguirá reflejando y consolidando los privilegios de clase. Dar beca completa a algunos solicitantes de familias menos ricas no puede ocultar el hecho de que la lógica comercial y el tono social de estas instituciones son fijados por hijos de familias acomodadas. Las compañías que cobran alta tarifas por cursos en línea sin valor tendrán ganancias cada vez mayores...

Podría continuar, pero no creo que esa imagen sombría sea inevitable, aunque por el momento parece horriblemente verosímil. Espero que presentarla en términos tan crudos ayude, al menos, a prestarle atención.

Una conclusión que se podría sacar es que no se puede defender a las universidades en términos apropiados sin cuestionar al mismo tiempo algunas premisas del discurso público general sobre el crecimiento económico. Permítanme ser claro. No sugiero aquí que intentemos cambiar la motivación humana común sobre la prosperidad, y menos aún que regresemos a un comunalismo pseudo primitivo en el que todos confeccionamos nuestras propias sandalias y cultivamos nuestros propios cereales. Pero aunque casi todos vivimos parte de nuestra vida conforme a creencias y objetivos distintos al de maximizar la riqueza, tenemos grandes dificultades para articular los valores que informan esas experiencias comunes, y nos parece casi imposible volver operativos esos valores y sus ideales conexos en la discusión pública de los bienes sociales. Esa es una razón para que la tarea parezca tan desalentadora. No se puede hacer una defensa adecuada de las universidades simplemente en términos de contribución a la prosperidad 
económica, pero tratar de cambiar los términos del discurso público general puede parecer más ambicioso y quijotesco.

Permítanme entonces terminar con una reflexión muy general. $\mathrm{Si}$ el lenguaje que empleamos para hablar de las universidades las representa como instituciones que proporcionan una capacitación vocacional estrecha para el empleo y la aplicación de tecnología para promover el crecimiento económico, y si el lenguaje que usamos para hablar de los estudiantes los representa como consumidores que van de compras al supermercado educativo solo porque proporciona el empleo futuro más remunerativo al menor costo, ese es el tipo de universidades y el tipo de educación con los que terminaremos. Es, por tanto, de suma importancia que intentemos formular una concepción diferente y más adecuada de "para" qué son las universidades, pues de lo contrario corremos el riesgo de deteriorar, o destruir, las características distintivas de las universidades y lo que las ha hecho tan valiosas para la humanidad en su búsqueda de una comprensión más plena y profunda. 